\title{
Extração e exportação de nutrientes pelo híbrido de mamona Savana: I - Macronutrientes
}

\section{Nutrients extraction and exportation by Savana castor bean hybrid: I - Macronutrients}

\author{
Carlos Alexandre Costa Crusciol'; Martha Santana do Nascimento²; \\ Adalton Mazetti Fernandes ${ }^{3 *}$; Maurício Dutra Zanotto ${ }^{4}$
}

\section{Resumo}

Híbridos de mamona de porte baixo e altamente produtivos, possivelmente necessitam de maior quantidade de macronutientes durante seu ciclo de desenvolvimento. Porém, no Brasil há carência de informações sobre extração e exportação de macronutrientes por híbridos de mamona de porte baixo, tanto no cultivo de safra como de safrinha. Objetivou-se com este trabalho avaliar a extração e a exportação de macronutrientes pelo híbrido de mamona Savana, de porte baixo, no cultivo de safra e safrinha. Os experimentos foram conduzidos na safra 2005/2006 e na safrinha de $2006 \mathrm{em}$ Latossolo Vermelho distroférrico. Utilizou-se o delineamento em blocos casualizados, com quatro repetições. As parcelas foram constituídas pelas épocas de coletas de plantas, as quais foram compostas por 6 fileiras de plantas de $5 \mathrm{~m}$ de comprimento, no espaçamento de $0,45 \mathrm{~m}$ entre fileiras. As coletas foram realizadas aos 17, 31, 45, 59, 73, 97 e 120 dias após a emergência (DAE) durante a safra e aos 17, 31, 45, 59, 80, 100 e 120 DAE na safrinha. O acúmulo de macronutrientes pelo híbrido de mamona Savana foi lento até o início do florescimento (30 DAE), mas intensificou-se após essa época. O período de maior absorção de nutrientes ocorreu aos 65 e 90 DAE para o N, 70 e 80 DAE para o P, 60 DAE para o K e Mg, 55 e 60 DAE para o $\mathrm{Ca}$ e $\mathrm{S}$. As quantidades extraídas por hectare pelo híbrido Savana variaram de 155 a 31 $\mathrm{kg}$ de N, 17 a $3 \mathrm{~kg}$ de P, 71 a $13 \mathrm{~kg}$ de K, 56 a $12 \mathrm{~kg}$ de Ca, 28 a $4 \mathrm{~kg}$ de $\mathrm{Mg}$ e 29,5 a $7 \mathrm{~kg}$ de $\mathrm{S}$ na safra e safrinha, respectivamente. A produtividade de grãos foi maior no cultivo de safra, mas a extração e exportação de macronutrientes por tonelada de grãos foram semelhantes entre as safras. Entre $40 \% \mathrm{e}$ $50 \%$ do $\mathrm{N}$ e $\mathrm{S}$, e a maior parte do $\mathrm{Mg}, \mathrm{K}$, e Ca acumulados nas plantas retornaram ao solo com os restos culturais, mas menos de $35 \%$ do $\mathrm{P}$ permaneceu na palhada.

Palavras-chave: Ricinus communis, nutrição mineral, curvas de absorção, taxas de absorção, produtividade de grãos

\begin{abstract}
Low height castor bean hybrids and highly productive possibly need larger quantity of macronutients during its development cycle. However, in Brazil there is little information on extraction and exportation of macronutrients by low height castor bean hybrids, as on season as out-of-season growing. This study aimed to evaluate the nutrients extraction and exportation by Savana hybrid castor bean on season and out-of-season growing. The experiments were conducted during the season of 2005/2006 and out-ofseason of 2006 in an Oxisol. The experimental design was a randomized block with four replications.
\end{abstract}

1 Prof. Titular do Dept ${ }^{\circ}$ de Produção Vegetal (Agricultura), Faculdade de Ciências Agronômicas, FCA, Universidade Estadual Paulista, UNESP, Botucatu, SP. Bolsista em produtividade pelo CNPq. E-mail: crusciol@fca.unesp.br

$2 \mathrm{Dr}^{\mathrm{a}}$ em Agronomia (Agricultura), FCA/UNESP, Botucatu, SP. E-mail: martha@agriconsult.com.br

3 Doutorando em Agronomia (Agricultura), FCA/UNESP, Botucatu, SP. E-mail: adaltonfernandes@hotmail.com

4 Prof. Assistente Dr. do Dept ${ }^{\circ}$ de Produção Vegetal (Agricultura), FCA/UNESP, Botucatu, SP. E-mail: zanotto@fca.unesp.br

* Autor para correspondência 
The plots were consisted by harvest times of plants, which were composed by six plant rows to $5 \mathrm{~m}$, spaced $0.45 \mathrm{~m}$ between rows. Samples were collected at 17, 31, 45, 59, 73, 97 and 120 days after emergence (DAE) during the season and at 17, 31, 45, 59, 80; 100 and 120 DAE in the out-of-season. The nutrients accumulation by Savana hybrid was small until the flowering (30 DAE), but intensified after this period. The period of greatest nutrient absorption occurred at 65 and $90 \mathrm{DAE}$ for N, 70 and 80 $\mathrm{DAE}$ for $\mathrm{P}, 60 \mathrm{DAE}$ for $\mathrm{K}$ and $\mathrm{Mg}, 55$ and $60 \mathrm{DAE}$ for $\mathrm{Ca}$ and $\mathrm{S}$. The amounts absorbed per hectare by hybrid Savana ranged 155 to $31 \mathrm{~kg}$ of N, 17 to $3 \mathrm{~kg}$ of P, 71 to $13 \mathrm{~kg}$ of K, 56 to $12 \mathrm{~kg}$ of Ca, 28 to $4 \mathrm{~kg}$ of $\mathrm{Mg}$ and 29,5 to $7 \mathrm{~kg}$ of S in season and out-of-season, respectively. The yield was higher in growing season, but the nutrients extraction and exportation per ton of grain were similar among the seasons. Among $40 \%$ and $50 \%$ of $\mathrm{N}$ and $\mathrm{S}$ and most part of $\mathrm{Mg}, \mathrm{K}$ and $\mathrm{Ca}$ accumulated in the plants returned to soil with crop residues, but less than $35 \%$ of $P$ remained in the residues.

Key words: Ricinus communis, mineral nutrition, absorption curves, absorption rates, yield

\section{Introdução}

A produção nacional de mamona (Ricinus communis L.) ainda é muito baixa. Na safra 2010/2011 a área cultivada com essa oleaginosa foi de 195.100 ha e a produção nacional foi de 132.700 toneladas (CONAB, 2011). Porém, devido à perspectiva de utilização do óleo da mamona como fonte energética na produção de biocombustível, as áreas cultivadas com essa oleaginosa vem aumentando nas últimas safras (CHAVES et al., 2009), inclusive na região Centro-Sul do País (CONAB, 2011), em que a mamoneira é cultivada em grandes áreas.

Com a expansão do cultivo, o fator nutrição mineral têm recebido maior importância (CHAVES et al., 2009), já que o crescimento e a produtividade da mamoneira estão diretamente relacionados com a nutrição adequada da cultura. Porém, estudos sobre marcha de absorção de nutrientes pela mamoneira são escassos na literatura brasileira. As informações existentes na literatura sobre exportação e absorção de nutrientes na cultura da mamona foram obtidas nas décadas de 50 (CANECCHIO FILHO; FREIRE, 1958) e 70 (NAKAGAWA; NEPTUNE, 1971), com cultivares de ciclo vegetativo longo, porte alto e desuniformidade de maturação, adaptadas apenas à colheita manual.

Considerando que recentemente o cultivo da mamona tem sido feito em grandes áreas, utilizando híbridos de porte baixo, adaptados aos sistemas de produção mecanizados e altamente produtivos
(SILVA et al., 2010), provavelmente, as necessidades nutricionais dessa cultura foram alteradas, pois, esses materiais são de ciclo precoce e apresentam elevada produtividade de grãos e homogeneidade de maturação. Assim, como a produtividade é maior e o ciclo menor, possivelmente, a demanda por nutriente num curto espaço de tempo é muito superior àquela observada nas cultivares tradicionais de ciclo longo e crescimento indeterminado.

Com o objetivo de aumentar a produtividade e a competitividade dessa cultura, têm-se realizado estudos sobre nutrição mineral com macronutrientes (LAVRES JÚNIOR et al., 2005; 2009) e adubação (SEVERINO et al., 2006; SILVA et al., 2007; ALMEIDA JÚNIOR et al., 2009; OLIVEIRA et al., 2010) em cultivares de mamona de porte baixo. Entretanto, ainda não existem dados na literatura sobre marcha de absorção de macronutrientes em híbridos de porte anão, tanto na época de safra em que essa oleaginosa tem sido inserida nos sistemas de rotação/sucessão de culturas (SILVA et al., 2010), como no período de safrinha, em que essa cultura têm se tornado uma importante opção de cultivo (MORO; CRUSCIOL; CARVALHO, 2011).

Dessa forma, torna-se necessário conhecer a dinâmica de acúmulo de macronutrientes ao longo do ciclo, de híbridos de mamona de porte baixo, bem como os períodos de maior exigência desses elementos, para que seja possível realizar adubações balanceadas, de forma a disponibilizar os nutrientes no solo em quantidades e épocas que assegurem a obtenção do máximo potencial produtivo. 
Objetivou-se com este trabalho avaliar a extração e a exportação de macronutrientes pelo híbrido de mamona Savana, de porte baixo, no cultivo de safra e safrinha.

\section{Material e Métodos}

Os experimentos foram conduzidos na Fazenda Experimental Lageado no Município de Botucatu, SP ( $48^{\circ} 26^{\prime} \mathrm{W}$ e $22^{\circ} 51^{\prime} \mathrm{S}$ e $740 \mathrm{~m}$ de altitude). O solo do local é um Latossolo Vermelho distroférrico, manejado há seis anos no sistema plantio direto. Durante a condução dos experimentos foram determinadas diariamente as temperaturas máximas e mínimas e a precipitação pluvial (Figura 1).

Figura 1. Precipitação (】), temperaturas máxima (-) e mínima (-) registradas durante a condução dos experimentos e posicionamento do momento da emergência, florescimento e colheita do híbrido de mamona Savana na safra 2005/06 e na safrinha 2006.

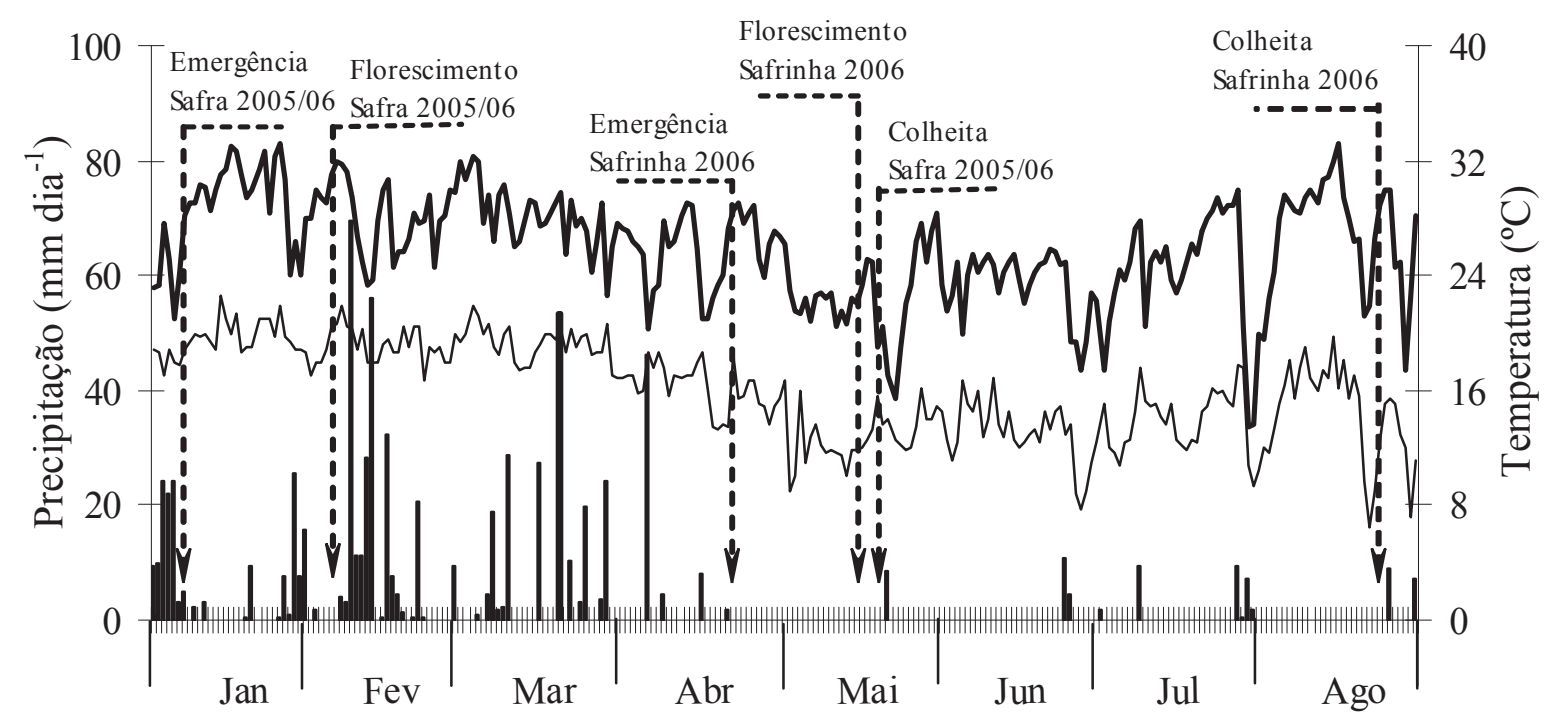

Fonte: Elaboração dos autores.

O delineamento experimental utilizado foi o de blocos casualizados, com quatro repetições. As parcelas foram constituídas pelas épocas de coletas de plantas, as quais foram realizadas aos 17, 31, 45, 59, 73, 97 e 120 DAE, durante a safra, e aos 17, 31, $45,59,80,100$ e 120 DAE, durante o cultivo de safrinha. As parcelas foram constituídas de 6 fileiras de plantas de $5 \mathrm{~m}$ de comprimento. Considerouse como bordadura, as duas fileiras de plantas da extremidade da parcela e $1 \mathrm{~m}$ de ambos os lados.

Antes da instalação dos experimentos realizaram-se amostragens na camada de 0-0,20 m para determinação das características químicas do solo (RAIJ et al., 2001), cujos resultados para safra foram: $\mathrm{MO}=24,0 \mathrm{~g} \mathrm{dm}^{-3}, \mathrm{pH}\left(\mathrm{CaCl}_{2} 0,01 \mathrm{~mol} \mathrm{~L}^{-1}\right)$ $=5,1, \mathrm{P}$ (resina) $=16,0 \mathrm{mg} \mathrm{dm}{ }^{-3}, \mathrm{~K}^{+}, \mathrm{Ca}^{2+}, \mathrm{Mg}^{2+}$, $\mathrm{H}+\mathrm{Al}$ e $\mathrm{CTC}=1,5,31,17,38$ e $87 \mathrm{mmol}_{\mathrm{c}} \mathrm{dm}^{-3}$, respectivamente, e saturação por bases de $56 \%$. Na safrinha, os resultados da análise de solo foram: $\mathrm{MO}=36,0 \mathrm{~g} \mathrm{dm}^{-3}, \mathrm{pH}\left(\mathrm{CaCl}_{2} 0,01 \mathrm{~mol} \mathrm{~L}^{-1}\right)=5,1, \mathrm{P}$ (resina) $=28,0 \mathrm{mg} \mathrm{dm}^{-3}, \mathrm{~K}^{+}, \mathrm{Ca}^{2+}, \mathrm{Mg}^{2+}, \mathrm{H}+\mathrm{Al} \mathrm{e} \mathrm{CTC}$ $=1,3,26,13,51$ e $92 \mathrm{mmol}_{\mathrm{c}} \mathrm{dm}^{-3}$, respectivamente, e saturação por bases de $45 \%$. 
Foi feita a dessecação das plantas espontâneas das áreas com glyphosate $\left(1,8 \mathrm{~kg}\right.$ do i.a ha $\left.{ }^{-1}\right)$ e a semeadura da mamona na safra foi realizada no dia 23/12/2005 sobre palhada de aveia. Na safrinha, a semeadura foi feita em área adjacente ao cultivo de safra, em 03/04/2006, sobre palhada de milho. Em ambos os experimentos, utilizaram-se sementes do híbrido comercial Savana, tratadas com fungicida carboxin-thiran (60 g $100 \mathrm{~kg}^{-1}$ de sementes do i.a.) e

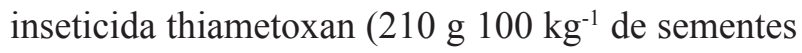
do i.a.). Foi usado espaçamento de $0,45 \mathrm{~m}$ entre linhas e 25.000 plantas ha-1. $^{-1}$

O híbrido Savana é de porte baixo, ciclo semiprecoce (160 dias), floresce por volta dos 42 dias após a emergência (DAE), apresenta $75 \%$ de flores femininas, boa rusticidade, altura média de 1,60 $\mathrm{m}$, frutos indeiscentes, boa debulha, produtividade média de $1.600 \mathrm{~kg} \mathrm{ha}^{-1}$, adequado para colheita mecanizada.

A adubação de semeadura foi realizada com base na análise de solo e nas recomendações de Savy Filho et al. (1999), aplicando-se $250 \mathrm{~kg} \mathrm{ha}^{-1}$ do formulado NPK 08-28-16+4,5\% de S + 0,5\% de Zn. Na safra a emergência ocorreu em 08/01/2006 e na safrinha em 23/04/06. Em cobertura foram aplicados 50 $\mathrm{kg} \mathrm{ha}^{-1}$ de $\mathrm{N}$ na forma de nitrato de amônio aos 20 DAE, quando as plantas apresentavam-se com 4-5 folhas totalmente expandidas. A distribuição do fertilizante foi realizada sobre a superfície do solo ao lado e aproximadamente $10 \mathrm{~cm}$ das fileiras de plantas.

Para o controle de plantas daninhas foram realizadas aplicações dos herbicidas setoxidim (184 $\mathrm{g} \mathrm{ha}^{-1}$ do i.a.) e clorimurom etílico (20 $\mathrm{g} \mathrm{ha}^{-1}$ do i.a.). Realizaram-se aplicações dos fungicidas procimidona (150 $\mathrm{g} \mathrm{ha}^{-1}$ do i.a.) e iprodiona (150 $\mathrm{g}$ ha $^{-1}$ do i.a.) para o controle de mofo cinzento (Botrytis ricini) no início e 20 dias após o florescimento.

Em cada época de coleta, retirou-se de cada parcela a parte aérea de 4 plantas seqüenciadas de uma fileira de plantas. As plantas amostradas foram separadas em caule, folhas e estruturas reprodutivas, lavadas e secadas em estufa de circulação forçada de ar a $65{ }^{\circ} \mathrm{C}$ por $168 \mathrm{~h}$ e pesadas. Os dados de matéria seca (MS) associados às épocas de coleta de plantas foram usados para a obtenção das curvas de acúmulo de MS durante o ciclo.

Após pesadas, as amostras foram moídas em moinho tipo Wiley e determinaram-se os teores de macronutrientes, segundo metodologia descrita por Malavolta, Vitti e Oliveira (1997). Com os dados de teores de macronutrientes e quantidade de MS, calcularam-se as quantidades de macronutrientes acumuladas em cada parte da planta e na parte aérea. As taxas de acúmulo de macronutrientes na parte aérea e nas estruturas reprodutivas foram obtidas por meio da derivada primeira da equação ajustada da quantidade acumulada na parte aérea e nas estruturas reprodutivas, respectivamente.

A colheita da safra e da safrinha foi realizada aos 120 DAE. Para a avaliação da produtividade de grãos, foram colhidas, manualmente, as plantas contidas na área útil da parcela, ou seja, em 4 linhas de $3 \mathrm{~m}$ de comprimento. Os cachos foram trilhados, os grãos pesados e, posteriormente, calculou-se a produtividade de grãos em $\mathrm{kg} \mathrm{ha}^{-1}$. Os valores da massa de 100 grãos e a produtividade de grãos foram padronizados para o teor de água de $80 \mathrm{~g} \mathrm{~kg}^{-1}$ (base úmida). A exportação de macronutrientes foi obtida a partir dos dados de produtividade e dos teores de macronutrientes nos grãos.

Os dados obtidos foram submetidos à análise de variância. Os efeitos das épocas de coletas de plantas para as variáveis acúmulo de MS e de nutrientes foram avaliados mediante análise de regressão, com auxílio do "software" SigmaPlot 10.0.

\section{Resultados e Discussão}

Em ambas as safras, o acúmulo de MS no caule, folhas e parte aérea foi pequeno até o início do florescimento (31 DAE), porém, após esse período, os acúmulos de MS intensificaram-se em proporções diferentes entre as safras (Figura 2). Os caules 
acumularam MS até próximo ao final do ciclo em ambas as safras, mas o acúmulo de MS nas folhas aumentou até aos 60 DAE na safrinha e até aos 73 DAE na safra, sofrendo reduções nas fases seguintes devido à senescência e queda de folhas (Figura 2). Outros autores também observaram senescência foliar e abscisão de folhas em cultivares de mamona de porte anão, em época semelhante à observada no presente estudo (CHAVES et al., 2009; DANTAS JÚNIOR et al., 2010), demonstrando que o máximo desenvolvimento das folhas no híbrido Savana ocorre por volta dos 60 a 70 DAE, à semelhança do que ocorre em cultivares e híbridos de porte baixo.

Figura 2. Acúmulo de matéria seca no caule (a), folhas (b), estruturas reprodutivas (c), parte aérea (d), e taxas de acúmulo de matéria seca nas estruturas reprodutivas (e) e na parte aérea (f) do híbrido de mamona Savana na safra 2005/06 e na safrinha 2006. **: significativo a $1 \%$ de probabilidade pelo teste $\mathrm{F}$.
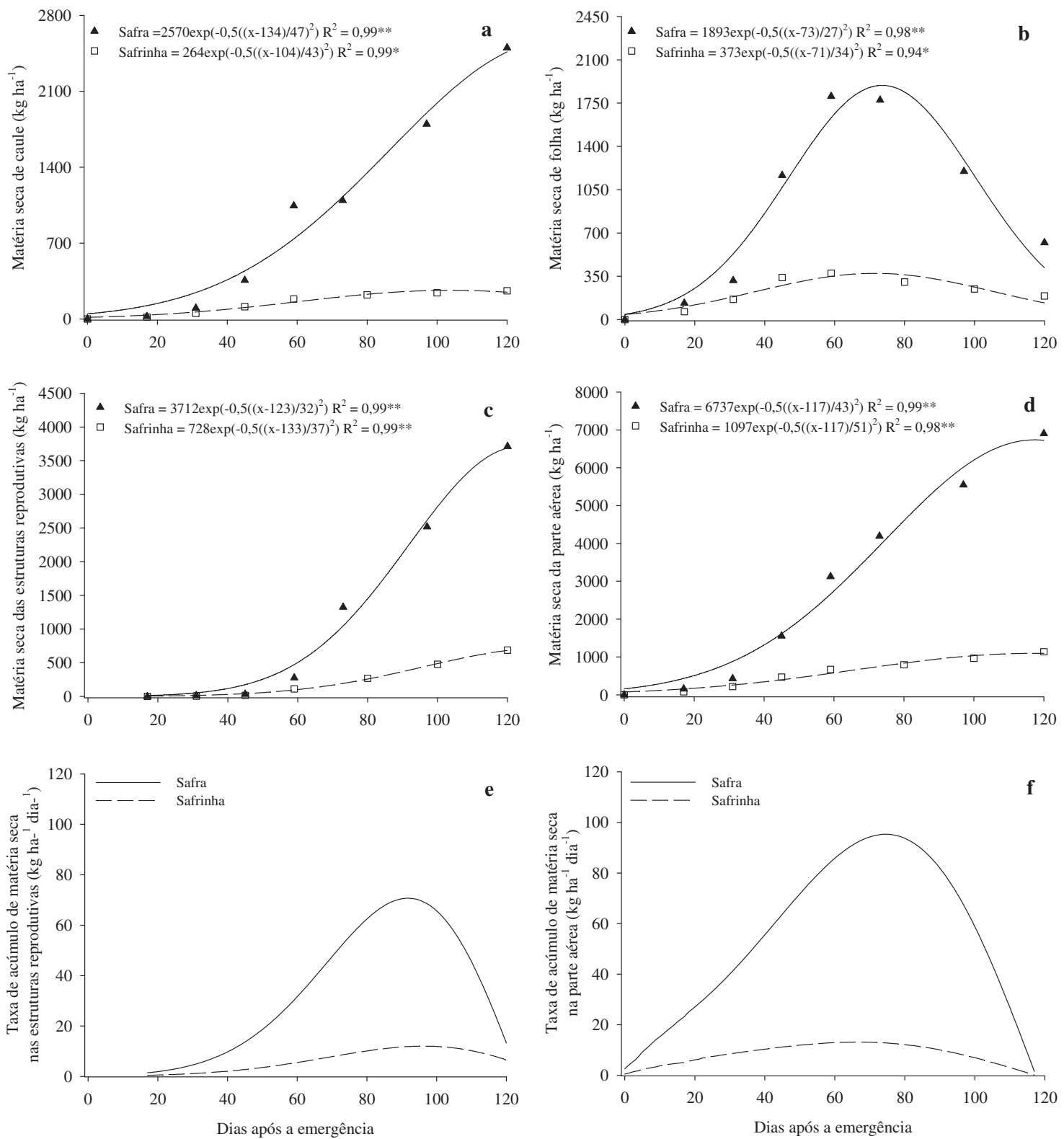

Fonte: Elaboração dos autores. 
Nos primeiros 20 a 30 dias após o florescimento houve o desenvolvimento simultâneo do caule, folhas e estruturas reprodutivas (Figura 2). Entretanto, a partir dos 60 DAE a intensidade de acumulação de MS nas estruturas reprodutivas foi maior, provavelmente, devido ao direcionamento de parte dos fotoassimilados dos outros tecidos para o desenvolvimento deste órgão, já que os grãos em formação atuam como drenos de fotoassimilados ocasionando, desta forma, redução da área e MS foliar (TAIZ; ZEIGER, 2004; DANTAS JÚNIOR et al., 2010).

Na parte aérea o acúmulo de MS intensificou-se após o florescimento (31 DAE), em ambas as safras, em função do crescimento intenso das estruturas reprodutivas (Figura 2). Verificou-se que houve acúmulo de MS na parte aérea até o final do ciclo, quando as plantas atingiram os acúmulos máximos de $6.904 \mathrm{~kg} \mathrm{ha}^{-1}$ na safra e $1.139 \mathrm{~kg} \mathrm{ha}^{-1}$ na safrinha. $\mathrm{O}$ menor crescimento e o menor acúmulo de MS na safrinha foram reflexos da menor disponibilidade hídrica nessa época de cultivo (Figuras 1 e 2).

Os teores de macronutrientes sofreram variação ao longo do ciclo da cultura nas safras estudadas (Tabelas 1 e 2). Em ambas as safras os maiores teores de $\mathrm{N}$ e $\mathrm{S}$ ocorreram na seguinte ordem: folhas, estruturas reprodutivas e caule, o que está de acordo com os resultados obtidos por Lavres Júnior et al. (2005). Esses autores observaram maior teor de $\mathrm{N}$ e $\mathrm{S}$ nas folhas em comparação com o caule e as raízes da mamoneira, cultivar Íris.

Já os maiores teores de $\mathrm{P}$ foram observados nas estruturas reprodutivas, folhas e caules, respectivamente (Tabelas 1 e 2). Nakagawa, Neptune e Muraoka (1982) observaram aumento no teor de $\mathrm{P}$ da planta de mamona em resposta à adubação fosfatada e constataram que a maior concentração desse elemento ocorreu nas estruturas reprodutivas, o que está de acordo com os resultados obtidos. Em solos arenosos de baixa fertilidade foi observado que mais de $80 \%$ de todo $\mathrm{P}$, contido nos frutos da mamoneira, estavam acumulados nas sementes (HOCKING, 1982), demonstrando que as sementes de mamona são fortes drenos de P. Esse maior teor de $\mathrm{P}$ nas estruturas reprodutivas devese ao fato que esse elemento, em comparação aos demais macronutrientes, acumula-se em maiores proporções nos grãos do que na biomassa da planta (HAAG et al., 1967).

Nas fases iniciais da cultura os teores de K foram superiores aos observados próximo da colheita (Tabelas 1 e 2). Especialmente, nas fases finais do ciclo houve uma tendência de maiores teores de $\mathrm{K}$ nas estruturas reprodutivas, enquanto que nas folhas e caule os teores foram semelhantes. Constatou-se que houve diminuição nos teores foliares de $\mathrm{N}$, $\mathrm{P}$ e $\mathrm{K}$ na fase final do cultivo de safra, indicando que houve remobilização desses nutrientes para as demais partes da planta (Tabela 1).

O Ca ocorreu em maiores teores nas folhas e em menores teores nas estruturas reprodutivas (Tabelas 1 e 2). Os menores teores de $\mathrm{Ca}$ nas estruturas reprodutivas devem-se ao efeito de diluição causado pelo rápido crescimento das estruturas reprodutivas (Figura 2c), pois como o Ca não é translocado em grandes quantidades para frutos e órgãos de armazenamento (MARSCHNER, 1995), o crescimento acelerado desse órgão proporcionou a manutenção dos baixos níveis de Ca. Mesmo sob condição de deficiência de $\mathrm{Ca}$, o teor desse nutriente no limbo foliar da mamoneira ainda é superior ao teor no caule e raízes (LAVRES JÚNIOR et al., 2005), evidenciando a baixa mobilidade desse elemento nos tecidos. Verificou-se que os menores teores $\mathrm{Mg}$ foram observados nas estruturas reprodutivas, porém no caule e folhas os teores foram semelhantes (Tabelas 1 e 2).

Quanto à absorção de macronutrientes, verificase que as quantidades acumuladas no caule, nas fases iniciais, foram pequenas em ambas as safras, porém, a partir dos $30 \mathrm{DAE}$, o acúmulo intensificouse (Figuras 3a, 4a, 5a, 6a, 7a e 8a). No cultivo de safra, o acúmulo de macronutrientes foi maior que na safrinha, e apenas o $\mathrm{N}$ e o $\mathrm{S}$ foram acumulados até 
o final do ciclo, enquanto que os demais nutrientes atingiram os acúmulos máximos entre 90 e 100 DAE (Figuras 3a, 4a, 5a, 6a, 7a e 8a). Na safrinha, o $\mathrm{S}$ foi o único nutriente acumulado no caule até o final do ciclo, sendo que os demais nutrientes foram acumulados até 95 e 110 DAE (Figuras 3a, 4a, 5a, $6 a, 7 a$ e $8 a)$.

Tabela 1. Teores de macronutrientes no caule, folhas e estruturas reprodutivas do híbrido de mamona Savana na safra 2005/06.

\begin{tabular}{|c|c|c|c|c|c|c|}
\hline DAE* & $\mathrm{N}$ & $\mathrm{P}$ & $\mathrm{K}$ & $\mathrm{Ca}$ & $\mathrm{Mg}$ & $\mathrm{S}$ \\
\hline & \multicolumn{6}{|c|}{$\underline{\mathrm{g} \mathrm{kg}^{-1}}$} \\
\hline & \multicolumn{6}{|c|}{ Caule } \\
\hline 17 & 19,0 & 2,1 & 27,9 & 11,8 & 7,4 & 1,1 \\
\hline 31 & 17,4 & 1,8 & 16,1 & 10,1 & 8,4 & 2,1 \\
\hline 45 & 21,5 & 2,1 & 19,4 & 16,5 & 8,2 & 3,1 \\
\hline 59 & 15,3 & 2,0 & 13,2 & 12,9 & 7,4 & 2,7 \\
\hline 73 & 13,0 & 2,0 & 14,7 & 12,0 & 5,8 & 2,6 \\
\hline 97 & 13,4 & 1,6 & 10,0 & 9,6 & 4,3 & 2,3 \\
\hline 120 & 13,9 & 1,2 & 5,3 & 7,3 & 2,9 & 2,0 \\
\hline & \multicolumn{6}{|c|}{ Folhas } \\
\hline 17 & 44,7 & 3,2 & 18,8 & 16,6 & 5,1 & 7,4 \\
\hline 31 & 41,0 & 3,4 & 17,9 & 24,3 & 8,1 & 9,1 \\
\hline 45 & 44,4 & 2,8 & 13,4 & 16,3 & 6,3 & 7,5 \\
\hline 59 & 41,4 & 3,0 & 12,2 & 27,1 & 7,6 & 8,7 \\
\hline 73 & 35,4 & 3,0 & 13,6 & 13,6 & 6,8 & 8,1 \\
\hline 97 & 31,6 & 2,5 & 9,9 & 21,3 & 7,7 & 8,0 \\
\hline 120 & 27,8 & 2,0 & 6,2 & 29,0 & 8,6 & 7,9 \\
\hline & \multicolumn{6}{|c|}{ Estruturas reprodutivas } \\
\hline 17 & 0,0 & 0,0 & 0,0 & 0,0 & 0,0 & 0,0 \\
\hline 31 & 52,7 & 6,5 & 19,5 & 7,0 & 2,8 & 4,4 \\
\hline 45 & 40,8 & 4,6 & 19,0 & 7,0 & 3,5 & 4,2 \\
\hline 59 & 38,3 & 4,1 & 16,7 & 6,5 & 3,3 & 5,6 \\
\hline 73 & 26,8 & 3,3 & 15,3 & 4,9 & 2,9 & 3,7 \\
\hline 97 & 27,1 & 3,3 & 13,8 & 4,7 & 3,0 & 4,3 \\
\hline 120 & 27,5 & 3,4 & 12,4 & 4,6 & 3,1 & 4,9 \\
\hline
\end{tabular}

*Dias após a emergência.

Fonte: Elaboração dos autores.

Nas folhas, os acúmulos máximos de nutrientes ocorreram em épocas diferentes do ciclo. $\mathrm{O} \mathrm{P}$ e o $\mathrm{K}$ na safrinha foram os nutrientes com acúmulo máximo mais precoce durante o ciclo, ou seja, aos 65 e 60 DAE, respectivamente (Figuras 4 b e 5b). Já o Ca teve o máximo acúmulo foliar mais tardio, ocorrendo aos 85 DAE na safra e 80 DAE na safrinha (Figuras 6b). Os demais macronutrientes tiveram acúmulo máximo foliar entre 70 e $75 \mathrm{DAE}$, independente da época de cultivo (Figuras 3b, 7b e 8b).
Na fase final do ciclo, os acúmulos foliares de nutrientes diminuíram em ambas as safras, porém com maior intensidade no cultivo de safra (Figuras $3 b, 4 b, 5 b, 6 b, 7 b$ e $8 b)$. A redução nas quantidades de N, P, K e S acumuladas nas folhas (Figuras 3b, $4 \mathrm{~b}$ e $5 \mathrm{~b}$ ) foi provocada pela queda de folhas (Figura 2) e pela redistribuição desses nutrientes para os grãos, principalmente, no cultivo de safra em que os teores foliares diminuíram (Tabela 1). Isso ocorre porque grande parte dos nutrientes acumulados 
nas folhas, durante o crescimento, é transferida, durante a senescência, para os órgãos reprodutivos ou em crescimento, e a morte foliar só ocorre após os processos de senescência remobilizar os nutrientes para outras partes da planta (SOUZA; FERNANDES, 2006). Em citros, o teor de N, $\mathrm{P}$ e $\mathrm{K}$ é menor nas folhas que estão próximas dos frutos, como conseqüência do processo de mobilização das reservas foliares desses elementos para os frutos (MALAVOLTA, 2006). O S também sofre redistribuição para atender as necessidades de órgãos novos em crescimento, entretanto, em proporções bem menores que o N (MALAVOLTA; MORAES, 2007), como pode ser constatado pela pequena queda nos teores foliares (Tabelas 1 e 2).

Tabela 2. Teores de macronutrientes no caule, folhas e estruturas reprodutivas do híbrido de mamona Savana na safrinha 2006.

\begin{tabular}{|c|c|c|c|c|c|c|}
\hline DAE* $^{*}$ & $\mathrm{~N}$ & $\mathrm{P}$ & $\mathrm{K}$ & $\mathrm{Ca}$ & $\mathrm{Mg}$ & $\mathrm{S}$ \\
\hline & \multicolumn{6}{|c|}{$\mathrm{g} \mathrm{kg}^{-1}$} \\
\hline & \multicolumn{6}{|c|}{ Caule } \\
\hline 17 & 22,7 & 2,6 & 42,1 & 15,0 & 6,9 & 2,9 \\
\hline 31 & 14,8 & 1,5 & 24,6 & 10,5 & 5,5 & 2,5 \\
\hline 45 & 11,6 & 1,4 & 21,0 & 12,3 & 5,2 & 2,4 \\
\hline 59 & 11,1 & 1,2 & 11,7 & 11,0 & 4,6 & 2,5 \\
\hline 80 & 10,5 & 1,1 & 8,8 & 10,0 & 4,1 & 2,9 \\
\hline 100 & 12,0 & 1,0 & 9,3 & 11,3 & 4,2 & 3,6 \\
\hline \multirow[t]{2}{*}{120} & 13,6 & 1,0 & 9,9 & 12,7 & 4,3 & 4,4 \\
\hline & \multicolumn{6}{|c|}{ Folhas } \\
\hline 17 & 48,1 & 3,3 & 19,6 & 12 & 3,2 & 6,7 \\
\hline 31 & 38,5 & 3,5 & 20,6 & 15,4 & 4,5 & 11,5 \\
\hline 45 & 33,2 & 2,5 & 15,7 & 16,1 & 4,2 & 10,8 \\
\hline 59 & 27,1 & 2,0 & 11,4 & 19,4 & 4,8 & 13,5 \\
\hline 80 & 29,5 & 2,0 & 11,7 & 21,5 & 5,8 & 11,5 \\
\hline 100 & 32,1 & 2,2 & 10,6 & 23,4 & 5,7 & 10,9 \\
\hline \multirow[t]{2}{*}{120} & 34,8 & 2,3 & 9,6 & 25,3 & 5,7 & 10,3 \\
\hline & \multicolumn{6}{|c|}{ Estruturas reprodutivas } \\
\hline 17 & 0,0 & 0,0 & 0,0 & 0,0 & 0,0 & 0,0 \\
\hline 31 & 36,9 & 4,9 & 24,1 & 3,4 & 3,4 & 5,8 \\
\hline 45 & 32,6 & 3,5 & 19,3 & 4,8 & 3,0 & 4,5 \\
\hline 59 & 27,5 & 2,9 & 17,4 & 4,9 & 2,8 & 5,2 \\
\hline 80 & 20,3 & 2,9 & 15,1 & 5,8 & 2,9 & 5,3 \\
\hline 100 & 25,8 & 3,0 & 14,0 & 5,3 & 2,8 & 5,6 \\
\hline 120 & 31,3 & 3,1 & 13,0 & 4,9 & 2,8 & 5,9 \\
\hline
\end{tabular}

*Dias após a emergência.

Fonte: Elaboração dos autores.

As diminuições nos acúmulos foliares de $\mathrm{Ca}$ e $\mathrm{Mg}$ (Figuras 6b e 7b) estão relacionadas com a redução da MS foliar (Figura 2b), pois os teores foliares desses elementos aumentaram na fase final do ciclo (Tabelas 1 e 2), demonstrando que as folhas são os principais drenos de $\mathrm{Ca}$ e $\mathrm{Mg}$ na planta e que esses nutrientes sofrem pouca remobilização nos tecidos.
Nas estruturas reprodutivas o acúmulo de macronutrientes foi pequeno até os $60 \mathrm{DAE}$, mas após esse período, as taxas de acúmulo de nutrientes intensificaram-se ocasionando maiores incrementos nas quantidades acumuladas neste órgão (Figuras $3 \mathrm{c}, 3 \mathrm{e}, 4 \mathrm{c}, 4 \mathrm{e}, 5 \mathrm{c}, 5 \mathrm{e}, 6 \mathrm{c}, 6 \mathrm{e}, 7 \mathrm{c}, 7 \mathrm{e}, 8 \mathrm{c}$ e $8 \mathrm{e})$. No cultivo de safra, os acúmulos de macronutrientes 
nas estruturas reprodutivas foram superiores aos da safrinha (Figuras 3c, 4c, 5c, 6c, 7c e 8c), devido a maior disponibilidade hídrica (Figura 1), que refletiu em maior acúmulo de MS (Figura 2) e maiores taxas de acúmulo de nutrientes (Figuras $3 \mathrm{e}, 4 \mathrm{e}, 5 \mathrm{e}, 6 \mathrm{e}, 7 \mathrm{e}$ e $8 \mathrm{e})$. Todos os macronutrientes foram acumulados nas estruturas reprodutivas até o final do ciclo, em ambas as safras, porém, entre 90 e 110 DAE verificou-se as máximas taxas de acúmulo neste órgão (Figuras 3c, 3e, 4c, 4e, 5c, 5e, 6c, 6e, 7c, 7e, 8c e 8e).

Figura 3. Acúmulo de $\mathrm{N}$ no caule (a), folhas (b), estruturas reprodutivas (c), parte aérea (d), e taxas de acúmulo de $\mathrm{N}$ nas estruturas reprodutivas (e) e na parte aérea (f) do híbrido de mamona Savana na safra 2005/06 e na safrinha 2006. **: significativo a $1 \%$ de probabilidade pelo teste $\mathrm{F}$.
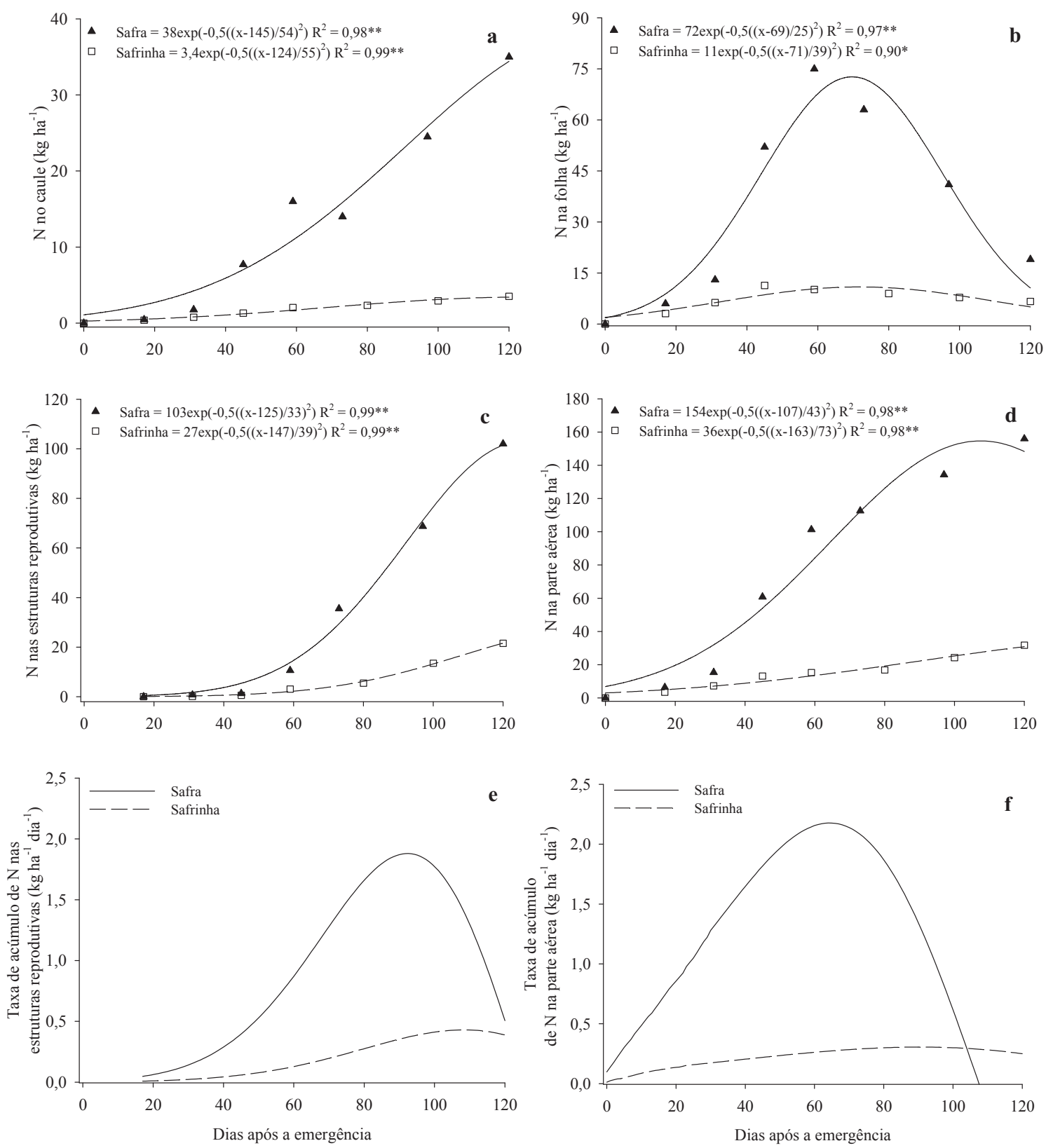

Fonte: Elaboração dos autores. 
As estruturas reprodutivas tornaram-se os drenos principais das plantas a partir dos $60 \mathrm{DAE}$, representando no final do ciclo entre $65 \%$ e $76 \%$ do total de N, P e K absorvido pelas plantas (Figuras 3,4 e 5). Essa elevada alocação desses nutrientes nas estruturas reprodutivas é reflexo da maior mobilidade desses nutrientes nos tecidos da planta, como pode ser observado pelas taxas similares de acúmulo desses elementos nas estruturas reprodutivas e na parte aérea (Figuras 3e, 4e e 5e).

A acumulação de $\mathrm{Ca}$ nas estruturas reprodutivas teve as menores proporções em relação aos demais nutrientes, sendo que os maiores acúmulos desse elemento ocorreram nas folhas (Figura 6). O baixo acúmulo de $\mathrm{Ca}$ nas estruturas reprodutivas ocorre pelo fato que órgãos de reserva, como os frutos e tubérculos, necessitam de concentrações mais baixas de Ca para o ótimo crescimento (MARSCHNER, 1995), o que foi constatado pelas baixas taxas de acúmulo deste elemento nas estruturas reprodutivas (Figura 6e). O Ca presente na seiva do xilema é translocado no sentido ascendente com o fluxo de transpiração (MARSCHNER, 1995). Assim, quando há adequada disponibilidade desse nutriente na solução do solo, o conteúdo deste nutriente nas folhas aumenta. Como os frutos tem baixa transpiração, a quantidade de Ca que chega à este órgão pelo xilema é baixa. Porém, isso não quer dizer que este nutriente seja fornecido aos frutos, predominantemente, pelo floema (MARSCHNER, 1995).

As proporções de $\mathrm{Mg}$ e de $\mathrm{S}$ acumuladas nas estruturas reprodutivas foram maiores que as de Ca (Figuras 6, 7 e 8), provavelmente, devido a maior mobilização de $\mathrm{Mg}$ e $\mathrm{S}$ para as estruturas reprodutivas, como pode ser evidenciada pelas menores diferenças entre os valores das taxas de acúmulo nas estruturas reprodutivas e na parte aérea (Figuras 7e, 7f, 8e e 8f).

$\mathrm{Na}$ safra, a absorção de nutrientes do solo foi maior que na safrinha com quantidades de 155 , 17, 71, 56, 28 e 29,5 $\mathrm{kg} \mathrm{ha}^{-1}$ de $\mathrm{N}, \mathrm{P}, \mathrm{K}, \mathrm{Ca}, \mathrm{Mg}$ e $\mathrm{S}$, respectivamente (Figuras 3d, 4d, 5d, 6d, 7d e 8d). Na safrinha a extração de macronutrientes foi de 31, 3, 13, 12, 4 e $7 \mathrm{~kg} \mathrm{ha}^{-1}$ de N, P, K, Ca, $\mathrm{Mg}$ e $\mathrm{S}$, respectivamente (Figuras 3d, 4d, 5d, 6d, $7 \mathrm{~d}$ e $8 \mathrm{~d}$ ). Em ambas as safras, os macronutrientes $\mathrm{N}, \mathrm{K}$ e Ca foram os mais absorvidos pelo híbrido Savana, o que também foi observado por Lavres Júnior et al. (2005) com a cultivar de mamona Íris, comprovando a alta exigência dessa cultura em por esses nutrientes. Nakagawa e Neptune (1971), observaram que o $\mathrm{K}$ foi o nutriente mais absorvido pela cultura da mamona seguido do $\mathrm{N}, \mathrm{Ca}, \mathrm{Mg}$ e $\mathrm{P}$, evidenciando que a ordem de maior absorção dos nutrientes pode variar com o sistema e a época de cultivo, e com a cultivar e/ou híbrido utilizado.

Com exceção do $\mathrm{N}$ e do $\mathrm{K}$, verificou-se que as quantidades dos demais macronutrientes absorvidas pelo híbrido Savana, foram maiores que àquelas obtidas por Nakagawa e Neptune (1971) com o cultivar de porte médio/alto "Campinas". Esses autores verificaram que essa cultivar extraiu ao longo do ciclo $156 \mathrm{~kg} \mathrm{ha}^{-1}$ de $\mathrm{N}, 5,3 \mathrm{~kg} \mathrm{ha}^{-1}$ de $\mathrm{P}$, $172 \mathrm{~kg} \mathrm{ha}^{-1}$ de $\mathrm{K}, 13,8 \mathrm{~kg} \mathrm{ha}^{-1}$ de Ca e $12,5 \mathrm{~kg} \mathrm{ha}^{-1}$ de $\mathrm{Mg}$. Esses resultados demonstram que híbridos de porte baixo, diferem das cultivares tradicionais quanto a absorção de nutrientes. 
Figura 4. Acúmulo de P no caule (a), folhas (b), estruturas reprodutivas (c), parte aérea (d), e taxas de acúmulo de P nas estruturas reprodutivas (e) e na parte aérea (f) do híbrido de mamona Savana na safra 2005/06 e na safrinha 2006. ** e * são: significativo a $1 \%$ e $5 \%$ de probabilidade pelo teste $\mathrm{F}$.
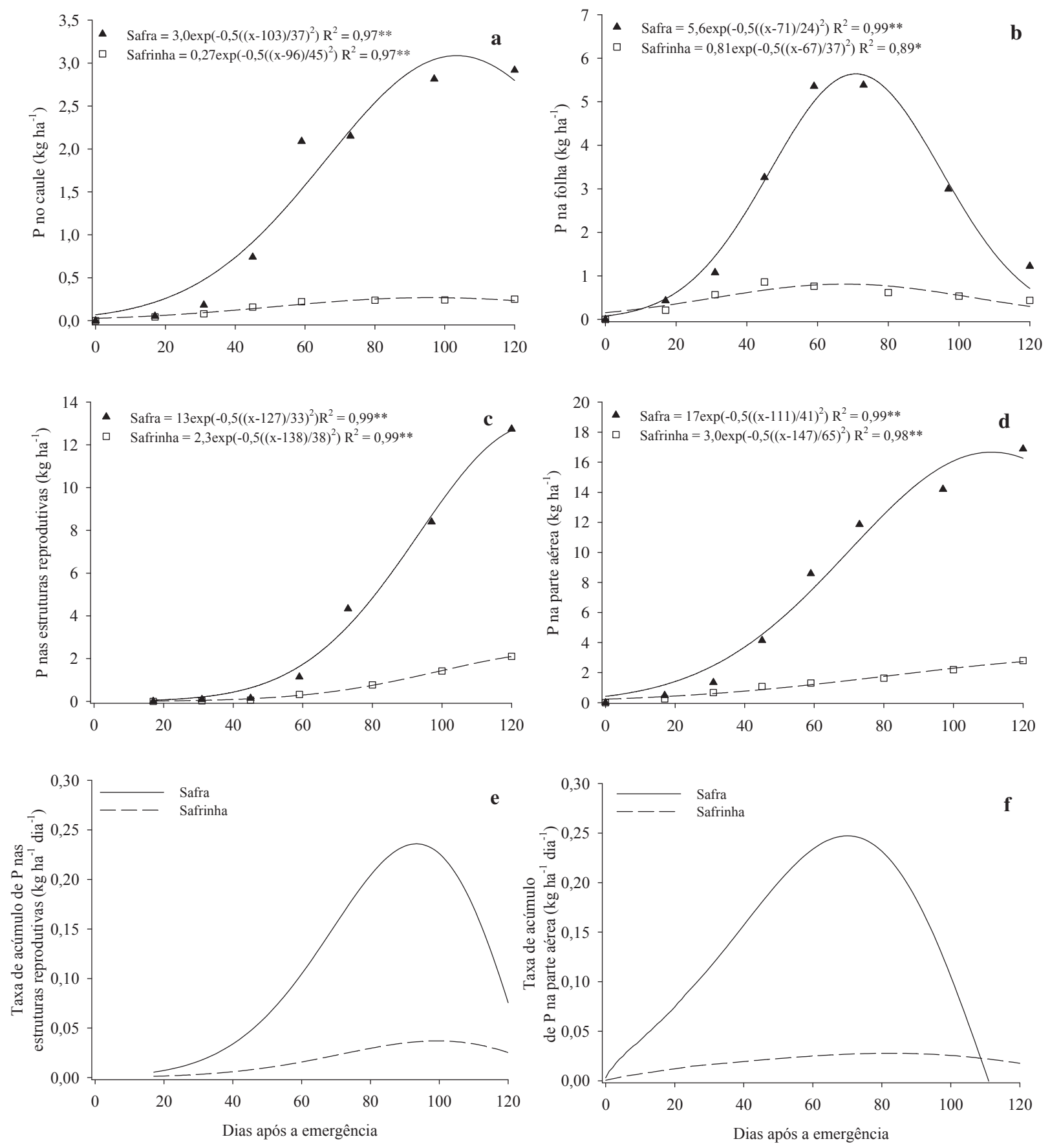

Fonte: Elaboração dos autores. 
Figura 5. Acúmulo de K no caule (a), folhas (a), estruturas reprodutivas (c), parte aérea (d), e taxas de acúmulo de K nas estruturas reprodutivas (e) e na parte aérea (f) do híbrido de mamona Savana na safra 2005/06 e na safrinha 2006. ** e * são: significativo a $1 \%$ e $5 \%$ de probabilidade pelo teste F.
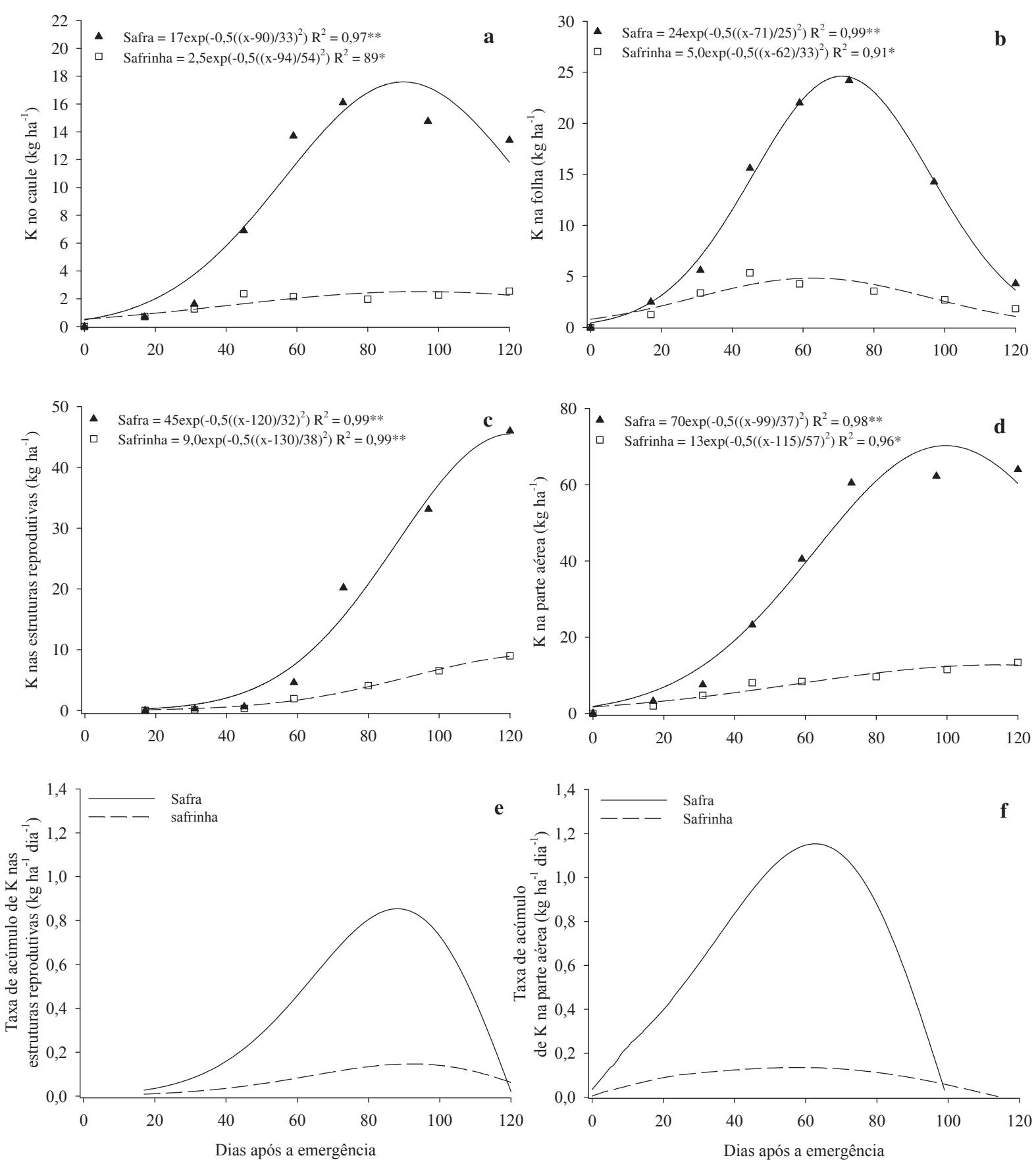

Fonte: Elaboração dos autores. 
Figura 6. Acúmulo de Ca no caule (a), folhas (b), estruturas reprodutivas (c), parte aérea (d), e taxas de acúmulo de Ca nas estruturas reprodutivas (e) e na parte aérea (f) do híbrido de mamona Savana na safra 2005/06 e na safrinha 2006. ** e* são: significativo a $1 \%$ e $5 \%$ de probabilidade pelo teste $\mathrm{F}$.
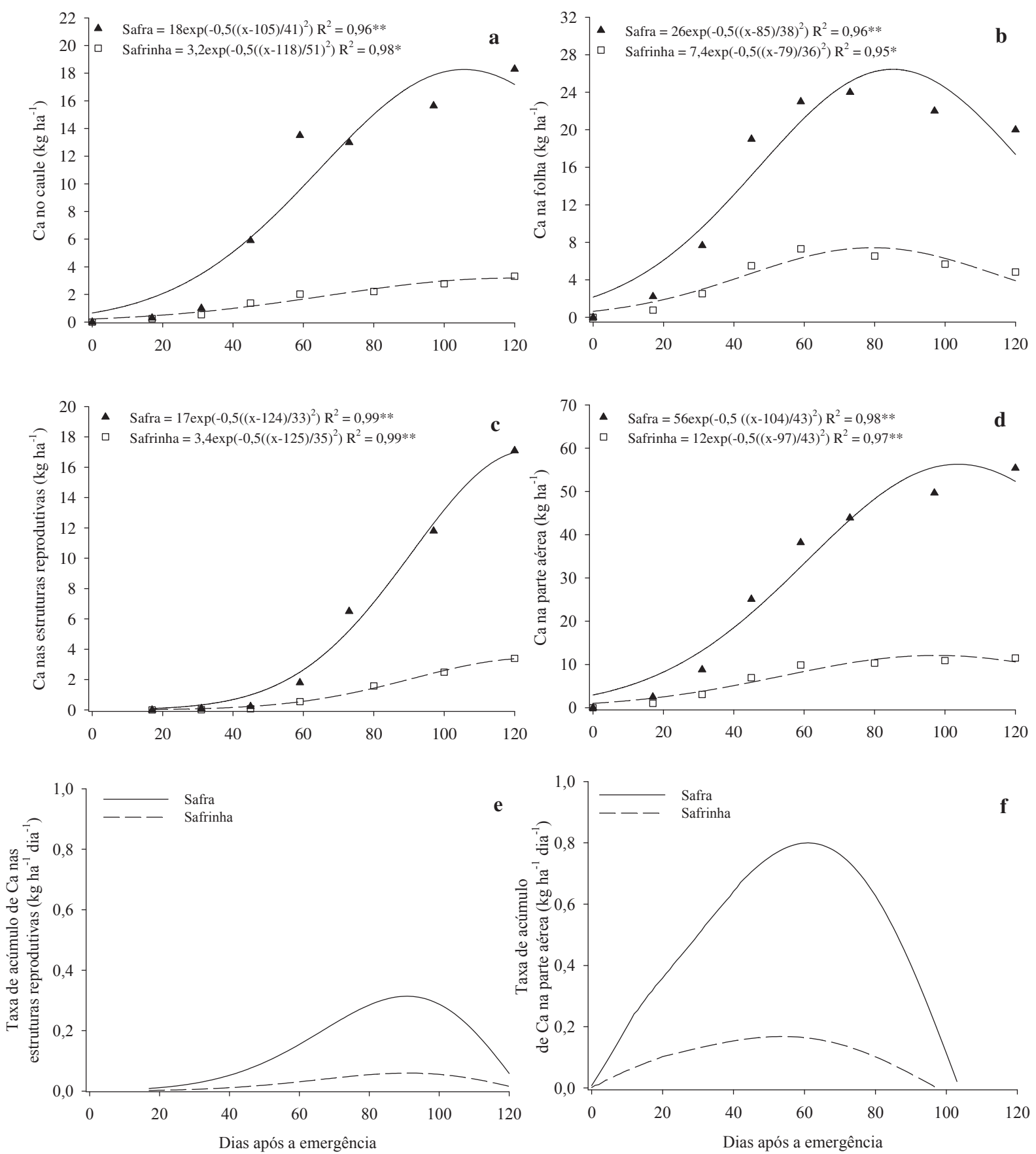

Fonte: Elaboração dos autores. 
Figura 7. Acúmulo de $\mathrm{Mg}$ no caule (a), folhas (b), estruturas reprodutivas (c), parte aérea (d), e taxas de acúmulo de Mg nas estruturas reprodutivas (e) e na parte aérea (f) do híbrido de mamona Savana na safra 2005/06 e na safrinha 2006. ** e * são: significativo a $1 \%$ e $5 \%$ de probabilidade pelo teste $\mathrm{F}$.
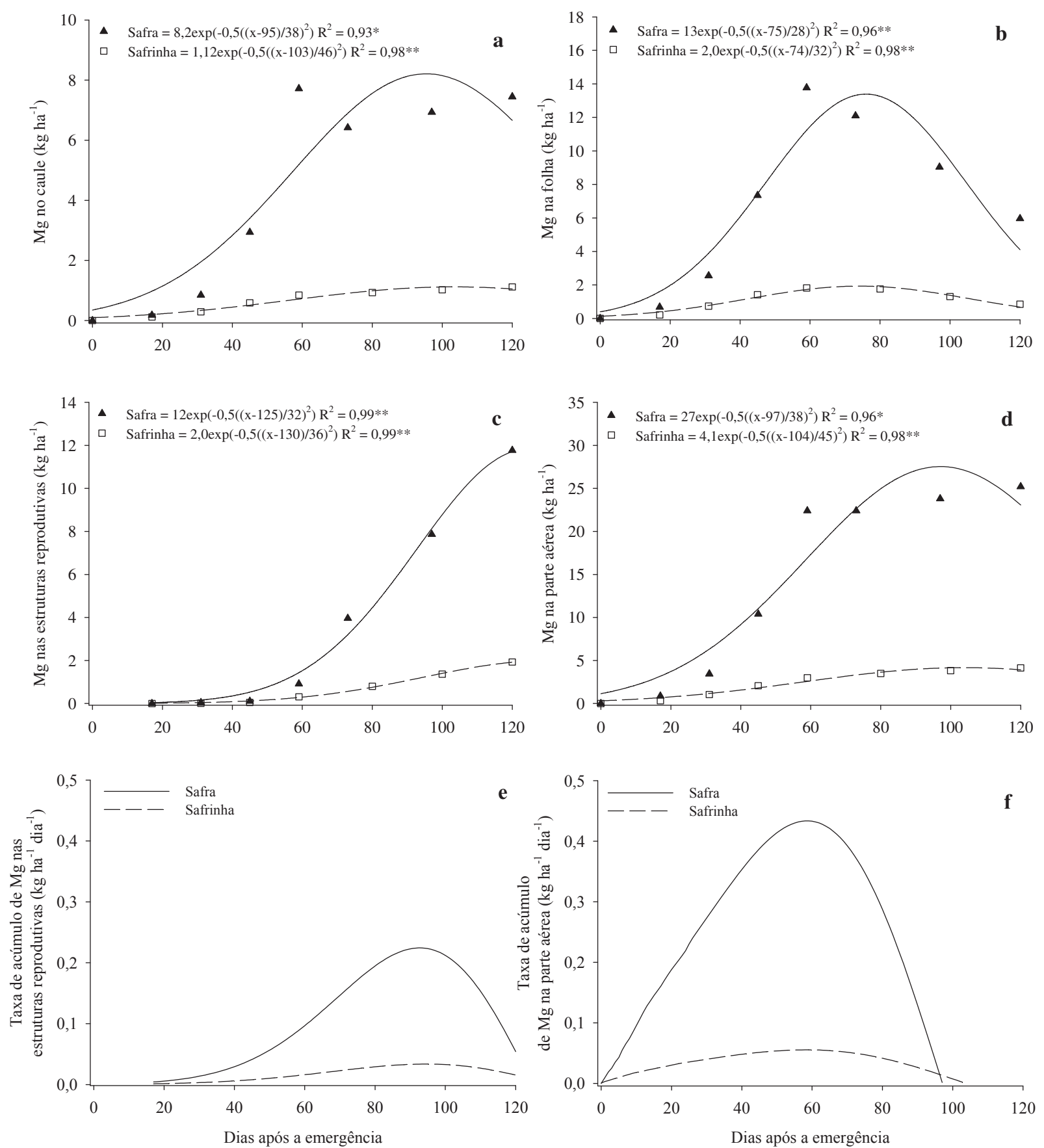

Fonte: Elaboração dos autores. 
Figura 8. Acúmulo de $\mathrm{S}$ no caule (a), folhas (b), estruturas reprodutivas (c), parte aérea (d), e taxas de acúmulo de $\mathrm{S}$ nas estruturas reprodutivas (e) e na parte aérea (f) do híbrido de mamona Savana na safra 2005/06 e na safrinha 2006. ** e * são: significativo a $1 \%$ e $5 \%$ de probabilidade pelo teste $\mathrm{F}$.
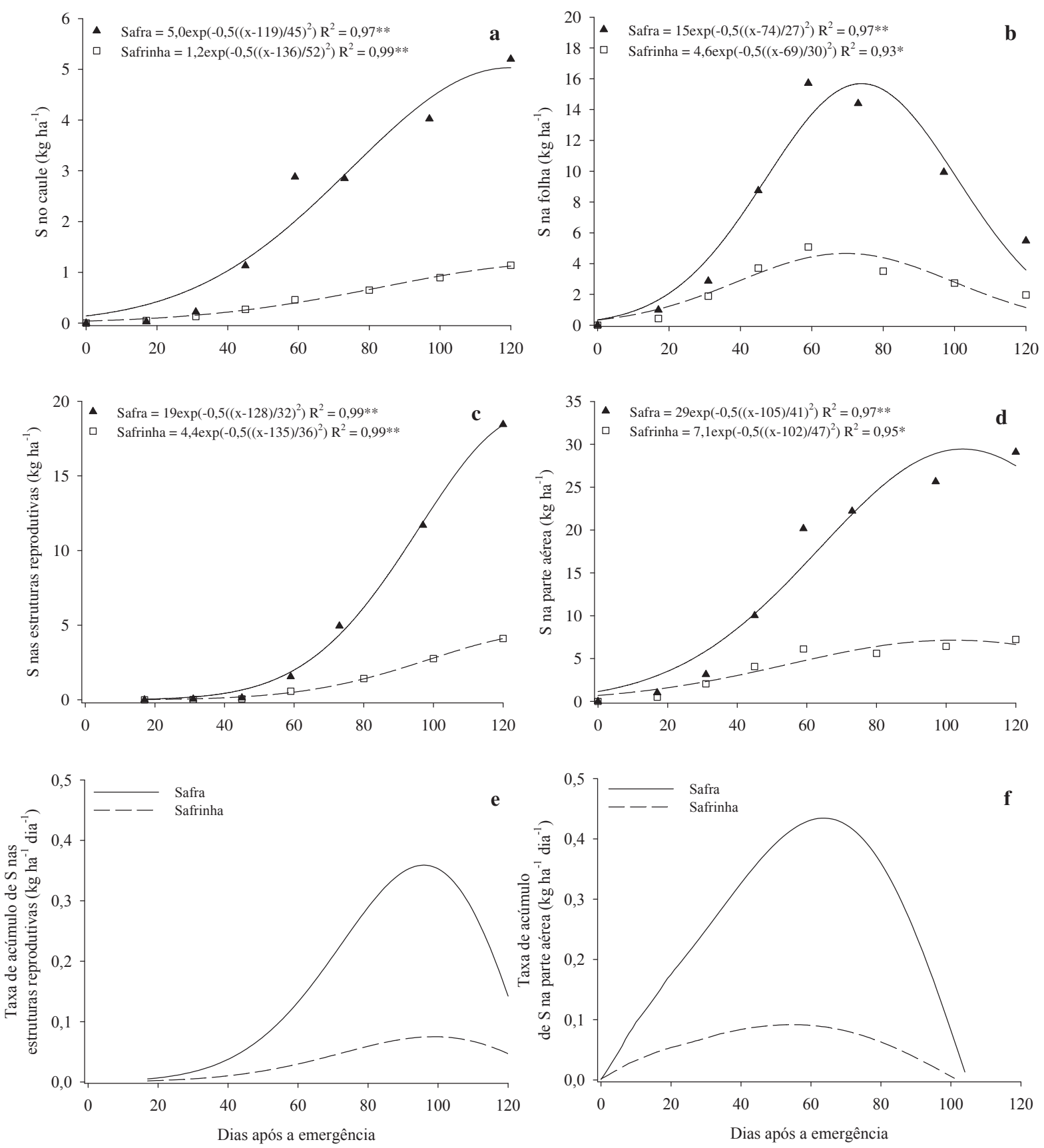

Fonte: Elaboração dos autores. 
Quanto à adubação utilizada, verificou-se que as quantidades de $\mathrm{N}\left(70 \mathrm{~kg} \mathrm{ha}^{-1}\right), \mathrm{K}\left(33 \mathrm{~kg} \mathrm{ha}^{-1}\right)$ e $\mathrm{S}$ $\left(11,3 \mathrm{~kg} \mathrm{ha}^{-1}\right)$, aplicadas via adubação foram maiores que as exigências totais desse híbrido durante a safrinha, mas não durante o cultivo de safra, em que a absorção foi maior e as quantidades absorvidas pelas plantas foram superiores àquelas fornecidas via adubação. Isto indica que atenção especial deve ser dada à adubação nitrogenada, potássica e sulfatada no cultivo desse híbrido, principalmente, no período de safra em que a absorção desses nutrientes foi maior que as doses aplicadas.
A produtividade de grãos foi maior no cultivo de safra em que houve a maior intensidade e distribuição de chuvas (Tabela 3 e Figura 1). Na safrinha, mesmo com maiores teores de N, K, Ca e $\mathrm{S}$ nos grãos, a exportação de nutrientes por área foi menor que na safra em que a produtividade foi maior (Tabela 3). Exceto para o K, as quantidades exportadas durante o cultivo de safra foram superiores àquelas estimadas por Canecchio Filho e Freire (1958) para a produção de $2.000 \mathrm{~kg} \mathrm{ha}^{-1} \mathrm{de}$ grãos.

Tabela 3. Produtividade de grãos, teor nos grãos, exportação por área, extração e exportação por tonelada de grãos, e exportação relativa de macronutrientes pelo híbrido de mamona Savana na safra 2005/06 e na safrinha 2006.

\begin{tabular}{|c|c|c|c|c|c|c|c|}
\hline Época de cultivo & Produtividade & $\mathrm{N}$ & $\mathrm{P}$ & $\mathrm{K}$ & $\mathrm{Ca}$ & $\mathrm{Mg}$ & $\mathrm{S}$ \\
\hline & $\mathrm{kg} \mathrm{ha}^{-1}$ & \multicolumn{6}{|c|}{ Teor nos grãos $\left(\mathrm{g} \mathrm{kg}^{-1}\right)$} \\
\hline Safra & 2.582 & 33,5 & 4,7 & 5,4 & 3,5 & 3,7 & 6,6 \\
\hline Safrinha & 494 & 38,3 & 4,0 & 7,3 & 4,2 & 3,1 & 7,9 \\
\hline \multicolumn{8}{|c|}{ Exportação por área $\left(\mathrm{kg} \mathrm{ha}^{-1}\right)$} \\
\hline Safra & 2.582 & 86,5 & 12,1 & 14,0 & 9,0 & 9,5 & 17,0 \\
\hline Safrinha & 494 & 18,9 & 2,0 & 3,6 & 2,1 & 1,5 & 3,9 \\
\hline \multicolumn{8}{|c|}{ Extração por tonelada de grãos $\left(\mathrm{kg} \mathrm{t}^{-1} \text { de grãos produzidos }\right)^{(1)}$} \\
\hline Safra & 2.582 & 60,0 & 6,6 & 27,5 & 21,7 & 10,8 & 11,4 \\
\hline Safrinha & 494 & 62,8 & 6,1 & 26,3 & 24,3 & 8,1 & 14,2 \\
\hline \multicolumn{8}{|c|}{ Exportação por tonelada de grãos ( $\mathrm{kg} \mathrm{t}^{-1}$ de grãos produzidos) } \\
\hline Safra & 2.582 & 33,5 & 4,7 & 5,4 & 3,5 & 3,7 & 6,6 \\
\hline Safrinha & 494 & 38,3 & 4,0 & 7,3 & 4,3 & 3,0 & 7,9 \\
\hline \multicolumn{8}{|c|}{ Exportação relativa pelos grãos $(\%)^{(2)}$} \\
\hline Safra & 2.582 & 55,8 & 71,2 & 19,7 & 16,1 & 33,9 & 57,6 \\
\hline Safrinha & 494 & 61,0 & 66,7 & 27,7 & 17,5 & 37,5 & 55,7 \\
\hline
\end{tabular}

${ }^{(1)}$ Dados obtidos com base na produtividade de grãos e nos valores de extração máxima obtidos nas figuras 2,3 , 4, 5, 6 e 7. (2) Exportação proporcional em relação as quantidades máximas absorvidas, obtidas nas figuras 2, 3, 4, 5,6 e 7.

Fonte: Elaboração dos autores.

A extração e exportação de nutrientes por área apresentaram grande variação entre as safras estudadas (Figuras 3d, 4d, 5d, 6d, 7d, 8d e Tabela 3). No entanto, a extração e exportação de nutrientes por tonelada de grãos produzidos apresentaram menor variação entre as safras (Tabela 3), o que demonstra que as quantidades de nutrientes extraídas e exportadas dependem do nível de produtividade.

Com relação à exportação relativa de nutrientes verificou-se que de todo $\mathrm{N}, \mathrm{P}$ e $\mathrm{S}$ acumulado pelas plantas mais de $50 \%$ foi exportado com os grãos, enquanto que as proporções de $\mathrm{Mg}, \mathrm{K}$ e $\mathrm{Ca}$ exportadas com os grãos foram inferiores a $35 \%$ do total extraído (Tabela 3). Isso evidencia que de $40 \%$ a $50 \%$ do $\mathrm{N}$ e $\mathrm{S}$, e a maior parte do $\mathrm{Mg}, \mathrm{K}$ e $\mathrm{Ca}$ acumulado nas plantas retorna ao solo com os restos culturais, diminuindo o esgotamento, enquanto que menos de $35 \%$ do $\mathrm{P}$ absorvido permanece nos restos culturais. 


\section{Conclusões}

O acúmulo de macronutrientes pelo híbrido de mamona Savana foi lento até o início do florescimento (30 DAE), mas intensificou-se após essa época. O período de maior absorção de nutrientes ocorreu aos 65 e 90 DAE para o N, 70 e $80 \mathrm{DAE}$ para o $\mathrm{P}, 60 \mathrm{DAE}$ para o $\mathrm{K}$ e $\mathrm{Mg}, 55$ e 60 DAE para o Ca e $\mathrm{S}$.

As quantidades extraídas por hectare pelo híbrido Savana variaram de 155 a $31 \mathrm{~kg}$ de N, 17 a $3 \mathrm{~kg}$ de $\mathrm{P}, 71$ a $13 \mathrm{~kg}$ de K, 56 a $12 \mathrm{~kg}$ de Ca, 28 a $4 \mathrm{~kg}$ de $\mathrm{Mg}$ e 29,5 a $7 \mathrm{~kg}$ de $\mathrm{S}$ na safra e safrinha, respectivamente.

A produtividade de grãos foi maior no cultivo de safra, mas a extração e exportação de macronutrientes por tonelada de grãos foram semelhantes entre as safras. Entre $40 \%$ e $50 \%$ do $\mathrm{N}$ e S, e a maior parte do $\mathrm{Mg}, \mathrm{K}$, e Ca acumulados nas plantas retornaram ao solo com os restos culturais, mas menos de $35 \%$ do $\mathrm{P}$ permaneceu na palhada.

\section{Agradecimentos}

Ao $\mathrm{CNPq}$ pela concessão de bolsa de Produtividade em Pesquisa ao primeiro autor.

\section{Referências}

ALMEIDA JÚNIOR, A. B.; OLIVEIRA, F. A.; MEDEIROS, J. F.; OLIVEIRA, M. K. T.; LINHARES, P. C. F. Efeito de doses de fósforo no desenvolvimento inicial da mamoneira. Revista Caatinga, Mossoró, v. 22, n. 1, p. 217-221, 2009.

CANECCHIO FILHO, V.; FREIRE, E. S. Adubação da mamoneira: experiências preliminares. Bragantia, Campinas, v. 17, n. 19, p. 243-259, 1958.

CHAVES, L. H. G.; BARROS JÚNIOR, G.; LACERDA, R. D.; CABRAL, P. C.; CUNHA, T. H. C. S. Resposta da mamoneira adubada com zinco e cobre. Engenharia Ambiental: Pesquisa e Tecnologia, Espírito Santo do Pinhal, v. 6, n. 6, p. 306-319, 2009.

COMPANHIA NACIONAL DE ABASTECIMENTO - CONAB. Safras: séries históricas. Disponível em:<http://www.conab.gov.br/OlalaCMS/uploads/ arquivos/11_07_15_16_50_48_mamonaseriehist.xls>. Acesso em: $\overline{2} 8$ jul. 2011.

DANTAS JÚNIOR, E. E.; CHAVES, L. H. G.; COSTA, F. A. M.; MESQUITA, E. F.; ARAÚJO, D. L. Crescimento de duas cultivares de mamoneira adubadas com potássio, cobre e zinco. Revista Caatinga, Mossoró, v. 23, n. 4, p. 97-107, 2010.

HAAG, H. P.; MALAVOLTA, E.; GARGANTINI, H.; BLANCO, H. G. Absorção de nutrientes pela cultura do feijoeiro. Bragantia, Campinas, v. 26, n. 30, p. 381-391, 1967.

HOCKING, P. J. Accumulation and distribution of nutrients in fruits of castor bean (Ricinus communis L.). Annals of Botany, Oxford, v. 49, n. 1, p. 51-62, 1982.

LAVRES JÚNIOR, J.; BOARETTO, R. M.; SILVA, M. L. S.; CORREIA, D.; CABRAL, C. P.; MALAVOLTA, E. Deficiências de macronutrientes no estado nutricional da mamoneira cultivar Íris. Pesquisa Agropecuária Brasileira, Brasília, v. 40, n. 2, p. 145-151, 2005.

LAVRES JÚNIOR, J.; NOGUEIRA, T. A. R.; CABRAL, C. P.; MALAVOLTA, E. Deficiências de macronutrientes no crescimento e na produção da mamoneira cultivar Íris. Revista Brasileira de Ciências Agrárias, v. 4, n. 4, p. 405-413, 2009.

MALAVOLTA, E. Manual de nutrição mineral de plantas. São Paulo: Agronômica Ceres, 2006. 638 p.

MALAVOLTA, E.; VITTI, G. C.; OLIVEIRA, S. A. Avaliação do estado nutricional de plantas: princípios e aplicações. Piracicaba: Potafós, 1997. 308 p.

MALAVOLTA, E.; MORAES, M. F. Fundamentos do nitrogênio e do enxofre na nutrição mineral das plantas cultivadas. In: YAMADA, T.; ABDALLA, S. R. S.; VITTI, G. C. (Ed.). Nitrogênio e enxofre na agricultura brasileira. Piracicaba: IPNI, 2007. p. 189-249.

MARSCHNER, H. Mineral nutrition of higher plants. 2. ed. London: Academic Press, 1995. 889 p.

MORO, E.; CRUSCIOL, C. A. C.; CARVALHO, L. L. T. Épocas de aplicação de nitrogênio para híbridos de mamona no sistema plantio direto em safrinha. Semina: Ciências Agrárias, Londrina, v. 32, n. 2, p. 391-410, 2011.

NAKAGAWA, J.; NEPTUNE, A. M. L. Marcha de absorção de nitrogênio, fósforo, potássio, cálcio e magnésio na cultura da mamoneira (Ricinus communis L.) cultivar Campinas. Anais da Escola Superior de Agricultura Luiz de Queiroz, v. 28, p. 323-337, 1971. 
NAKAGAWA, J.; NEPTUNE, A. M. L.; MURAOKA, T. Absorção e translocação de fósforo em dois cultivares de mamoneira (Ricinus communis L.), "Campinas" e "Guarani”. Anais da Escola Superior de Agricultura Luiz de Queiroz, v. 39, p. 319-335, 1982.

OLIVEIRA, J. P. M.; SCIVITTARO, W. B.; CASTILHOS, R. M. V.; OLIVEIRA FILHO, L. C. I. Adubação fosfatada para cultivares de mamoneira no Rio Grande do Sul. Ciência Rural, Santa Maria, v. 40, n. 8, p. 1835-1839, 2010.

RAIJ, B. van; ANDRADE, J. C.; CANTARELLA, H.; QUAGGIO, J. A. Análise química para avaliação da fertilidade de solos tropicais. Campinas: Instituto Agronômico, 2001. 284 p.

SAVY FILHO, A.; BANZATO, N. V.; BARBOZA, M. Z.; MIGUEL, A. M. R. O.; DAVI, L. O. C.; RIBEIRO, F. M. Mamona: In: COORDENADORIA DE ASSISTÊNCIA TÉCNICA INTEGRAL - CATI. Oleaginosas no estado de São Paulo: análise e diagnóstico. Campinas: CATI. 1999. 39 p. (Documento técnico, 107).
SEVERINO, L. S.; FERREIRA, G. B.; MORAES, C. R. A.; GONDIM, T. M. S.; FREIRE, W. S. A.; CASTRO, D. A.; CARDOSO, G. D.; BELTRÃO, N. E. M. Crescimento e produtividade da mamoneira adubada com macronutrientes e micronutrientes. Pesquisa Agropecuária Brasileira, Brasília, v. 41, n. 4, p. 563-568, 2006.

SILVA, A. G.; CRUSCIOL, C. A. C.; SORATTO, R. P.; COSTA, C. H. M.; FERRARI NETO, J. Produção de fitomassa e acúmulo de nutrientes por plantas de cobertura e cultivo da mamona em sucessão no sistema plantio direto. Ciência Rural, Santa Maria, v. 40, n. 10, p. 2092-2098, 2010.

SILVA, T. R. B.; LEITE, V. E.; SILVA, A. R. B. D. A.; VIANA, L. H. Adubação nitrogenada em cobertura na cultura da mamona em plantio direto. Pesquisa Agropecuária Brasileira, Brasília, v. 42, n. 9, p. 13571359, 2007.

SOUZA, S. R.; FERNANDES, M. S. Nitrogênio. In: FERNANDES, M. S. (Ed.). Nutrição mineral de plantas. Viçosa, MG: SBCS, 2006. p. 215-252.

TAIZ, L.; ZEIGER, E. Fisiologia vegetal. 3. ed. Porto Alegre: Artmed, 2004. 719 p. 